\title{
INOVAÇÃO E O SENTIDO DE VANGUARDA NO DESIGN GRÁFICO EDITORIAL
}

\section{INNOVATION AND THE MEANING EFFECT OF AVANT- GARDE IN EDITORIAL GRAPHIC DESIGN}

Marc Barreto Bogo ${ }^{1}$ 


\section{Resumo}

O mercado editorial de livros é marcado pela tradição e tem bem estabelecidos certos critérios de design que se mantêm constantes ao longo dos séculos. No entanto, alguns projetos gráficos de livros contemporâneos propõem mudanças na estrutura elementar do livro, apresentando uma intensa exploração formal. Uma editora brasileira que se destaca por seu investimento em design é a Cosac Naify, da qual selecionamos para análise uma série de livros específica, a Coleção Particular. Essa coleção constrói efeitos de sentido de inovação e de vanguarda por meio da exploração de seus projetos gráficos. A partir da moldura teórico-metodológica da Semiótica Discursiva, objetivamos compreender a maneira como se constroem tais efeitos de sentido. Concluímos que a vanguarda da Cosac Naify apresenta-se como um termo complexo, que une tradição e inovação, pois ao mesmo tempo em que a editora propõe acabamentos, materiais e processos produtivos contemporâneos, seus livros retomam a própria história do livro em construções discursivas e plásticas que propiciam uma sensibilização do leitor.

Palavras-Chave: Design editorial. Semiótica Discursiva. Inovação. Vanguarda.

\section{Abstract}

The publishing of books is well -marked by tradition and presents certain design traits that remain constant over the centuries. Nevertheless, some graphic projects of contemporary books propose changes in the basic structure of the book, exhibiting an intense design exploration. A Brazilian publishing house that stands out due to its investment in design is Cosac Naify, from which we selected for analysis a specific series of books called Coleção Particular. This collection creates certain effects of meaning through their graphic projects: the effects of innovation and avant-garde. Based on the theoretical and methodological framework of Discursive Semiotics, we aimed to understand how such meaning effects are created. We concluded that Cosac Naify's effect of avant-garde presents itself as a complex term that unites tradition and innovation, because their books propose contemporary materials and production processes but they also refer to the history of the book in their discursive and plastic constructions.

Keywords: Editorial design. Discursive Semiotics. Innovation. Avant-garde.

ISSN: 1808-3129

\footnotetext{
${ }^{1}$ Marc Barreto Bogo

marc_bogo@hotmail.com
} 


\section{INTRODUÇÃO}

Todo livro possui um projeto gráfico, feito por um designer ou não, bom ou não. Quando se fala em projeto gráfico de livro entende-se não somente o desenvolvimento de uma imagem de capa, mas sim todas as escolhas relativas à concretização material do livro: capa, papel utilizado, formato, margens, tipografia, imagens, diagramação etc. A função que hoje é realizada pelo designer gráfico, de planejar formalmente os livros, já foi executada ao longo da história por profissionais distintos: por escribas, por calígrafos, pelo próprio editor, por impressores, artistas, tipógrafos, entre outros. Muitos dos aspectos de um projeto gráfico de livro estão consolidados historicamente e a história do livro perpassa a própria história da escrita. Seu desenvolvimento deu-se ao longo de muitos séculos, ocorrendo por meio de sucessivas inovações tecnológicas, mas foi somente a partir do advento da impressão tipográfica, no século XV, que o livro adquiriu em definitivo sua configuração atual. Sua estrutura básica permanece fundamentalmente inalterada até hoje, sendo utilizada até mesmo em publicações singulares como livros de artistas, livros artesanais, publicações independentes etc. Há, portanto, uma valorização da tradição que é consolidada historicamente na configuração formal do livro.

Trabalhando a partir de um formato estabelecido que é constituído por páginas de papel impressas dobradas, costuradas pela lombada e encadernadas, que seguem um percurso organizacional lógico (capa, frontispício, sumário e assim por diante), o projeto gráfico do livro articula as particularidades que o fazem ser um objeto significante. São escolhas que dizem respeito à configuração formal do livro e que podem acarretar experiências de leitura muito diversas.

Com a popularização dos e-readers, tablets e smartphones, novas modalidades digitais de leitura surgiram nos últimos anos e algumas delas, como os e-books e os aplicativos interativos, são precipitadamente anunciadas como as "sucessoras dos livros" e vêm sendo introduzidas sistematicamente em nosso cotidiano. Enfrentando um avanço das publicações digitais, os volumes impressos passaram a ter seu modo tradicional de existência questionado. Nesse contexto, um dos caminhos indicados para os códices físicos é o de enfatizar justamente aquilo que lhes é próprio: sua materialidade. Muitos livros impressos contemporâneos evidenciam o que é particular em sua substância, e daí resultam os experimentos com as edições chamadas "especiais" dos livros, que exibem formatos diferentes, escolhas inusitadas de papéis, processos de impressão, dobras, costuras, cheiros, acabamentos, ilustrações, recortes, enfim, uma exploração dos formantes plásticos1.

Entendemos que o livro é um texto sincrético: além de linguagem verbal, utiliza-se da linguagem gráfica e muitas vezes também de outras linguagens visuais, como a fotografia, a gravura etc., bem como de uma linguagem gestual inscrita no objeto (a maneira de manuseá-lo), que se manifestam em uma totalidade composta por substâncias verbovisuais-espaciais-táteis. O design então se faz parte fundamental na constituição desse arranjo plástico do livro.

Considerando o contexto de afirmação da materialidade dos livros impressos

1 A plasticidade pode ser entendida como a organização do plano da expressão de uma dada manifestação. 
em relação a seus novos concorrentes (os e-books), vemos surgir no Brasil edições de livros com projetos gráficos de grande esmero e com um intenso fator de experimentação. A Cosac Naify é uma editora cuja missão parece ser a utilização da materialidade do produto impresso na construção de experiências que explorem justamente a fisicalidade da publicação. Elaine Ramos, designer da equipe dessa editora, expõe os seus valores ao produzir livros impressos: "Não faz sentido um livro que não se justifica como objeto, um livro que [não] tira partido do livro-obra, do livro-de -artista, que fazem uma afirmação da materialidade do livro" (citada por MACHADO, 2012). A editora, desse modo, se configura por explorar os traços plásticos do livro na construção de novas experiências de leitura.

É da Cosac Naify a publicação de um conjunto de obras bastante representativo desse cenário editorial: a série intitulada Coleção Particular. Tal coleção tem como proposta o lançamento de clássicos da literatura, principalmente com narrativas curtas, em edições nas quais o projeto gráfico faz parte da experiência de leitura. Questionando o paradigma de design vigente, seus livros falam da produção do livro, de sua própria forma, estrutura e história. Tais discursos são sempre manifestados a partir de um intrincado projeto gráfico que considera os elementos gráficos como parte fundamental no processo de produção de sentido do livro.

Os livros dessa coleção apresentam os mais diversos arranjos formais: capas costuradas, capas que simulam um embrulho de jornal, capas que desdobram-se para revelar uma enorme fotografia oculta, capas que são uma simples embalagem plástica etc.; páginas não-refiladas que precisam ser rasgadas para serem lidas, páginas dobradas com imagens ocultas em seu interior, páginas que escurecem progressivamente à medida que o livro avança, páginas com metade de seu bloco de texto disposto de ponta cabeça etc. Essa breve listagem exemplifica o tipo de recurso inesperado que os designers da Cosac Naify se valem em seus projetos, como veremos a seguir.

Interessados em perceber de que maneira os projetos gráficos contemporâneos fazem sentido, selecionamos essa coleção para a análise por representar, de certa maneira, o que há de mais relevante na produção nacional em se tratando da exploração do projeto gráfico de livro. A Cosac Naify se faz vista sempre como uma editora que investe em design, buscando proporcionar novas experiências táteis de leitura, e sua Coleção Particular é o bastião dessa empreitada editorial.

Para dar conta dos efeitos de sentido de inovação e de vanguarda que a Coleção Particular constrói - percebidos nas publicações tanto intuitivamente quanto após uma análise discursiva aprofundada -, nada mais pertinente que se valer de uma base teórica que trate justamente da investigação do sentido. A Semiótica então, por ser a disciplina que se ocupa do estudo da significação, é essencial na análise dos projetos gráficos desses livros, justamente por se propôr a investigar o que dizem as mais diversas manifestações e de que modo dizem aquilo que dizem.

A corrente teórica que fundamenta o presente trabalho é a Semiótica Discursiva, elaborada por Algirdas Julien Greimas e seus colaboradores, bem como seus desdobramentos plásticos e sensíveis realizados por Jean-Marie Floch, Eric Landowski e Ana Claudia de Oliveira. Ao se ocupar dos diferentes sistemas de linguagem postos em discurso, a Semiótica Discursiva ajuda-nos a encarar os livros como uma totalida- 
de de sentido que é verbovisual-espacial-tátil, e também a compreender os livros da Coleção Particular em relação aos diversos outros discursos que estão em circulação no mundo e que se relacionam a essas obras.

Seja nas escolhas de materiais, acabamentos e no tratamento gráfico, seja ao retomar certos aspectos da produção do livro, as obras da Coleção Particular apresentam um efeito de sentido que se repete em todas as publicações: a característica de vanguarda, de mostrar uma nova maneira de editar livros. Objetivamos aqui analisar os projetos gráficos dos livros da Coleção Particular, da editora Cosac Naify, visando compreender a maneira como se constrói esse efeito de sentido.

\section{A COLEÇÃO PARTICULAR DA COSAC NAIFY}

A editora Cosac Naify mantém sua sede na zona central da megalópole São Paulo. A localização na Pauliceia não é dessemantizada. Pelo contrário: vários sentidos advém daí. "Dinâmica", "inovadora", "pulsante", "vigorosa", são características que podem ser facilmente atribuídas tanto a uma, a editora, quanto à outra, a cidade que a abriga. É nas diversas ocorrências midiáticas e nas falas dos sujeitos coletivos que os atributos acima elencados se fazem constantes, construindo um efeito de sentido de vanguarda a partir dos modos como a editora se dá a ver socialmente. A Cosac Naify estabelece, pouco a pouco, uma ruptura no mercado editorial nacional. Semioticamente, é claro, o procedimento a ser tomado não é o de "aceitar" esse efeito de sentido de vanguarda como dado de antemão, mas sim perceber os modos como ele se constrói, a partir das diversas visibilidades da editora. Para isso, inicialmente lançamos um olhar sobre o lugar da Coleção Particular na estruturação da Cosac Naify.

A editora se organiza a partir de doze áreas de publicação, e é dentro da área de literatura que surge nosso corpus de pesquisa: a Coleção Particular. A série de livros publicados pela Cosac Naify é definida pela editora da seguinte maneira: "Clássicos da literatura ocidental, com narrativas breves, em edições nas quais o projeto gráfico faz parte da experiência de leitura e interfere na forma de experimentar o texto."

O título inicial da coleção, lançado no ano de 2004, foi Primeiro amor (fig. 1), obra do autor irlandês Samuel Beckett. O título, que já havia sido publicado no Brasil na década de 1980 por outras editoras, reapareceu nessa versão com tradução para o português de Célia Euvaldo. A obra é encadernada com a técnica chamada de "costura chinesa" e traz em suas páginas, além do texto verbal, quinze ilustrações da própria tradutora, que é também artista plástica. O projeto gráfico dessa edição foi realizado por Elaine Ramos. 


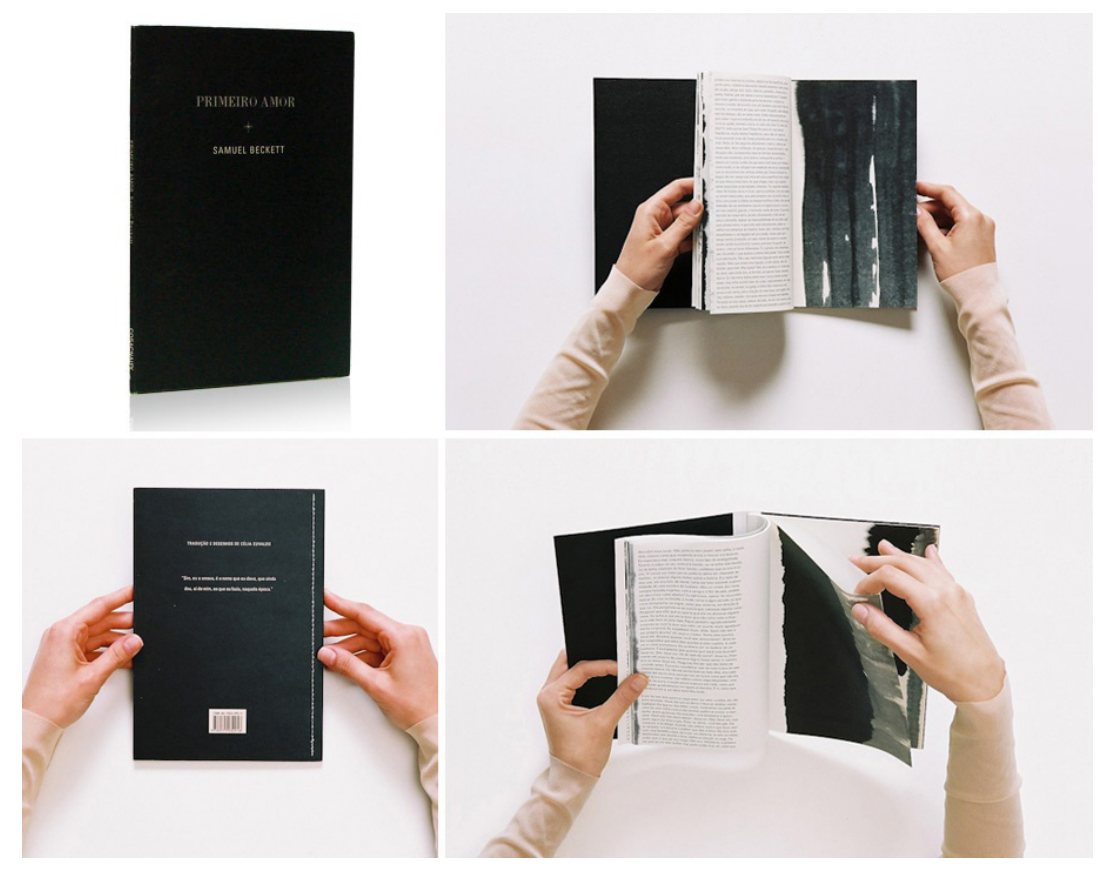

Figura 1: Primeiro amor, Samuel Beckett. Fonte: <editora.cosacnaify.com.br>.

Em seguida, houve a polêmica publicação de Bartleby, o escrivão (fig. 2), de Herman Melville, em 2005. Essa curta narrativa já havia sido publicada em português diversas vezes, porém nunca em uma edição como a da Cosac Naify. A edição referida possui uma costura em linha vermelha que une suas duas capas, forçando o leitor a descosturar a obra. Como as páginas não são refiladas, o leitor é obrigado a cortá-las com uma espátula plástica que acompanha o livro para poder ter acesso a seu conteúdo verbal, interagindo ainda mais com o objeto. Essa edição também possui seu projeto gráfico feito por Elaine Ramos.

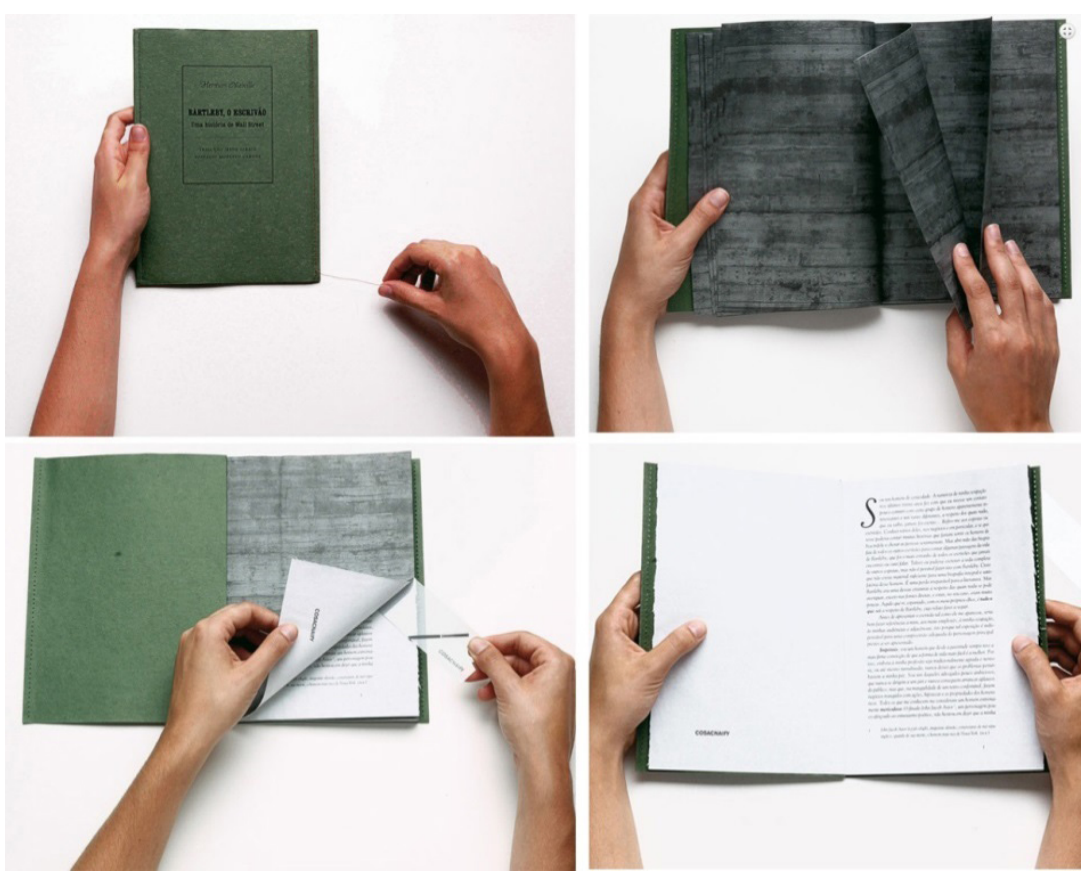

Figura 2: Bartleby, o escrivão, Herman Melville. Fonte: <editora.cosacnaify.com.br>. 
A terceira obra que faz parte da coleção é A fera na selva (fig. 3), de Henry James, lançada em 2007 (ano em que a editora comemorava dez anos de funcionamento). No livro da Cosac Naify, o projeto gráfico acompanha a evolução da narrativa pois, à medida que ela vai se tornando mais dramática, a gramatura das páginas do livro aumenta, as tonalidades do papel escurecem e o espaço entre as linhas do texto diminui. Ainda, a capa se desdobra como um pôster e revela duas fotografias em seu interior. O projeto gráfico dessa edição é de Luciana Facchini.

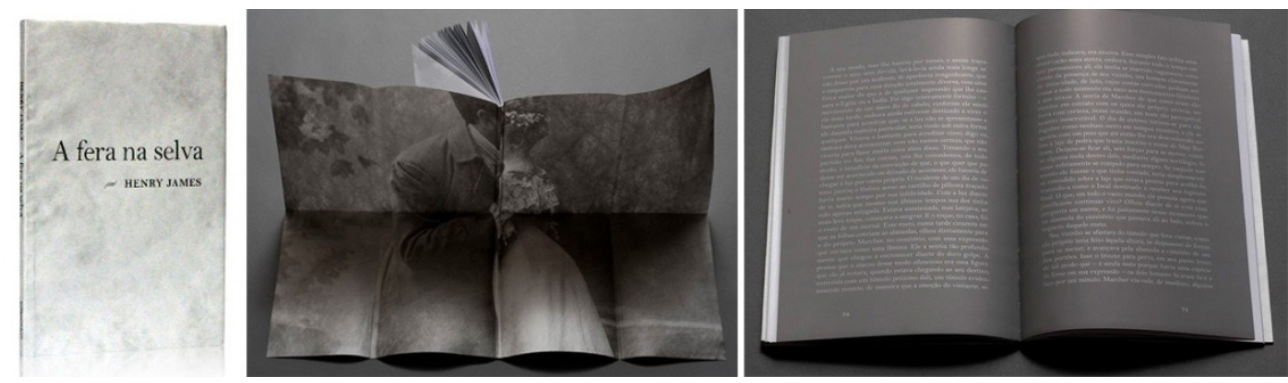

Figura 3: A fera na selva, Henry James. Fonte: <editora.cosacnaify.com.br>

O título A fera na selva foi o que inaugurou, de fato, a Coleção Particular. A designer Elaine Ramos, em entrevista para a página da própria editora, esclareceu o processo: "Na verdade, a coleção só foi pensada a partir deste lançamento, pois os dois outros livros que a integram, o Primeiro amor e Bartleby, já existiam. Todos têm o mesmo formato e propostas semelhantes. E como esses projetos tiveram bastante sucesso, montamos esta Coleção Particular." (COSAC NAIFY, 2013). Em outras palavras, mesmo não tendo sido pensados como constituintes de uma coleção a priori, os títulos iniciais foram percebidos pela equipe da editora como possuindo "propostas semelhantes", isto é, como títulos que mantinham entre si relações interdiscursivas de algum modo e que compartilhavam uma certa lógica comum na elaboração de seus projetos gráficos. O fator mercadológico, a partir dos discursos da própria equipe da editora, também foi visto como fundamental para a constituição da coleção: Primeiro amor teve um êxito de crítica e de vendas maior que o esperado pela Cosac Naify, bem como Bartleby, o escrivão, que já soma várias reimpressões.

Constituída assim essa nova coleção, os títulos seguintes propuseram diferentes experimentações em seus projetos gráficos. São eles:

- Zazie no Metrô (fig. 4), de Raymond Queneau, publicado em 2009, com projeto gráfico de Elaine Ramos e Maria Carolina Sampaio.

- Flores (fig. 5), de Mario Bellatin, lançado também em 2009, com projeto gráfico assinado novamente por Elaine Ramos e Maria Carolina Sampaio.

- Museu do romance da Eterna (fig. 6), do argentino Macedonio Fernández, lançado no ano de 2010, com projeto gráfico desenvolvido por Elaine Ramos.

- Avenida Niévski (fig. 7), de Nikolai Gógol, publicado em 2012, com projeto gráfico de Elaine Ramos e Gabriela Castro.

Mais recentemente foram ainda acrescentados à coleção os títulos Cães heróis, 
também do autor Mario Bellatin, e $O$ passageiro secreto, de Joseph Conrad, no ano de 2015.

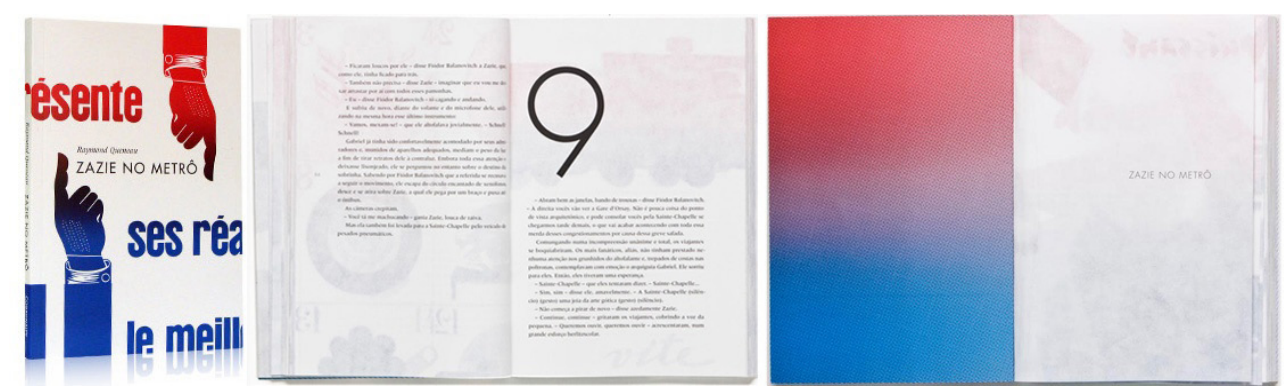

Figura 4: Zazie no metrô, Raymond Queneau. Fonte: <editora.cosacnaify.com.br>.

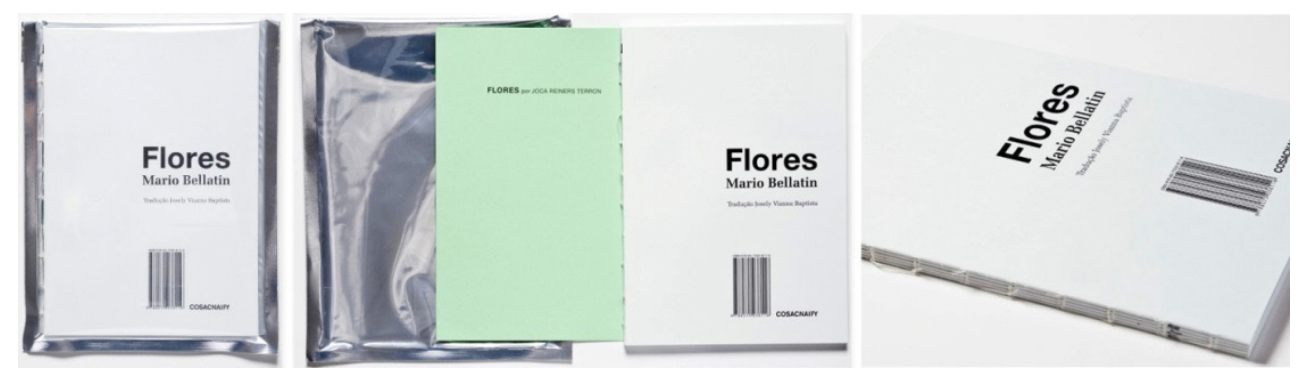

Figura 5: Flores, Mario Bellatin. Fonte: <editora. cosacnaify.com.br>.
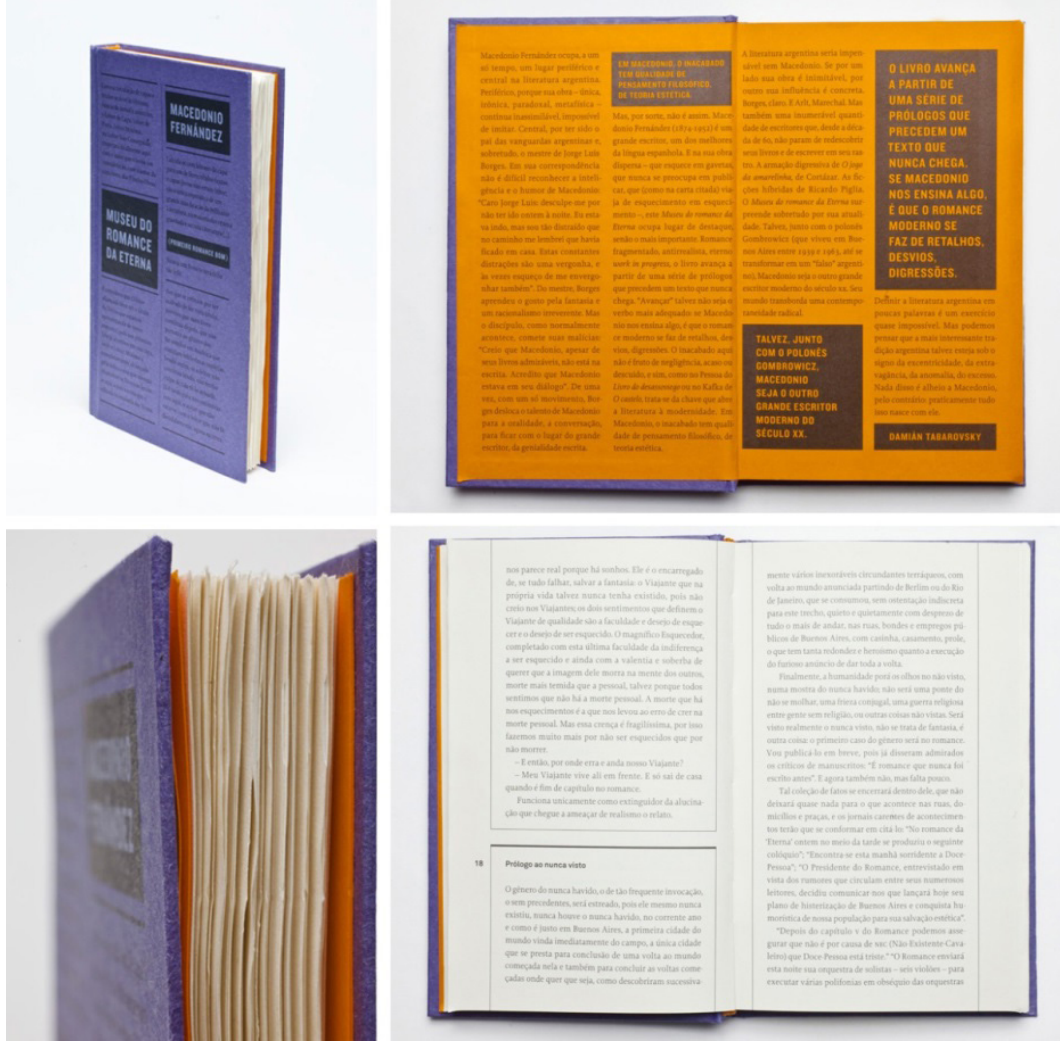

Figura 6: Museu do romance da Eterna, Macedonio Fernández. Fonte: <editora.cosacnaify.com.br>. 


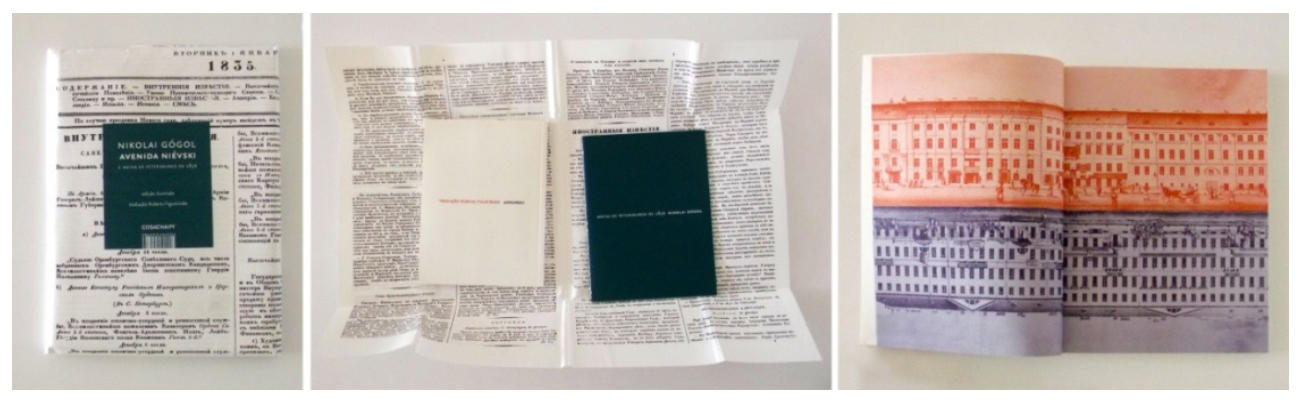

Figura 7: Avenida Niévski, Nikolai Gógol. Fonte: foto do autor.

Percebe-se prontamente que, entre os títulos da coleção, não há um padrão de repetição formal explícito: formatos, cores, materiais, acabamentos - ou seja, as escolhas do projeto gráfico - mudam a cada novo livro lançado, haja vista que dialogam com aquilo que é específico do verbal. Se não há um único projeto gráfico que é adaptado a cada livro, o que faz da coleção uma totalidade? Há certamente algumas escolhas enunciativas que são reiteradas nos projetos gráficos, a princípio independentes entre si, desse conjunto de obras que permitiriam considerá-las como partes de um todo coerente, ou seja, como partes de uma mesma coleção cuja identidade se reflete na identidade da própria editora.

A configuração identitária da editora, que é construída a partir dos seus discursos cuidadosamente planejados, pode ser encontrada a partir da verificação das isotopias e das suas reiterações. O conceito de isotopia se define como: "a recorrência de categorias sêmicas, quer sejam essas temáticas (ou abstratas) ou figurativas" (GREIMAS; COURTÉS, 2011, p. 276). Fiorin retoma essa ideia a partir do desenvolvimento teórico de Greimas, explicando a isotopia como aquela repetição, redundância ou recorrência de traços semânticos ao longo do discurso que oferece ao leitor um plano de leitura, um certo modo de ler o texto (FIORIN, 2011).

Aqui levamos em consideração não apenas um texto, mas um conjunto de textos-livros que em suas relações configuram uma coleção. Percebemos nas edições das obras da Coleção Particular algumas escolhas enunciativas que são recorrentes, e que configuram isotopias fundamentais para a compreensão dos sentidos de "inovação" e de "vanguarda" no mercado editorial brasileiro.

Uma primeira operação reiterada nos projetos gráficos da coleção é a de ruptura com os procedimentos comuns do mercado editorial nacional, do ponto de vista do design. Tal característica é percebida principalmente nos modos de encadernação adotados, todos bastante inusitados, por exemplo: um volume em costura chinesa; uma capa que se dobra sobre a quarta capa e se desdobra para revelar uma fotografia em seu interior; uma edição sem capa e com a costura aparente, envolta em um saco plástico etc. O caso mais exemplar é, certamente, Bartleby, o escrivão: a capa é costurada e as páginas não são refiladas, obrigando o leitor a rasgá-las para ter acesso ao verbal. Tal estratégia rompe, certamente, com a lógica daquilo que é praticado usualmente no mercado editorial.

O próprio efeito de sentido de vanguarda pode ser considerado uma segunda isotopia, já que está presente tanto na escolha das obras verbais quanto no design 
dos livros. Todos os autores selecionados possuem, de algum modo, esse caráter de liderança e de ruptura e se tornaram marcos da literatura em seus gêneros. Raymond Queneau, por exemplo, foi tido como linguisticamente ousado em Zazie no metrô ao explorar a linguagem coloquial francesa em seus diálogos; Macedonio Fernández foi uma figura importante do modernismo argentino; Herman Melville, assim como muitos outros vanguardistas, não teve suas obras bem recebidas pela crítica enquanto vivo e seu reconhecimento só veio após a morte. Visto que cada projeto gráfico parte do específico de seu texto verbal, essa temática geral da vanguarda é retomada no design de cada um dos livros. Ser vanguardista (seja no design dos livros, seja na escolha dos autores) não é apenas opor-se a um modo de produção cultural vigente, mas trata-se também de um diferencial estratégico de mercado, perfeitamente integrado aos valores econômicos contemporâneos.

Há ainda mais uma isotopia fundamental: todos esses livros constroem metadiscursos sobre o livro, pois a Coleção Particular, por meio de seus projetos gráficos, fala sobre a história do livro e sobre seus próprios processos produtivos. É essa última isotopia que vamos explorar melhor a seguir.

\section{PROCEDIMENTOS INTERDISCURSIVOS}

Por meio do modo como estão estruturados, os livros da Coleção Particular retomam aspectos diversos da história do livro, da forma do livro e de seu processo produtivo, adotando assim vários procedimentos interdiscursivos. Uma relação interdiscursiva é aquela que relaciona dois discursos distintos: quando um determinado discurso retoma elementos de outro discurso, ou seja, retoma escolhas enunciativas que foram concretizadas pelo outro, está criando uma relação entre discursos.

Ao longo da história do livro há recorrências diversas: materiais, formatos, acabamentos, processos produtivos que se repetem sincronicamente e que se modificam juntos diacronicamente, e nessa dinâmica configuram um discurso histórico sobre o objeto livro. Esses materiais, formatos e acabamentos consolidados historicamente são retomados no design dos livros da Coleção Particular. Os temas e figuras que se constituíram historicamente na formação do livro são o pano de fundo que serve de contexto para a compreensão dos projetos atuais e vanguardistas da coleção. Ao falar sobre livros, as obras da Cosac Naify constroem um metadiscurso do livro, em que cada livro é pensado a partir de outros livros.

Dada a pequena extensão desse artigo, vamos analisar com atenção os interdiscursos apenas nas duas primeiras publicações, para indicar de que maneira são construídas essas relações, e a seguir somente citaremos brevemente algumas das relações metadiscursivas encontradas nos demais livros.

O primeiro título da Coleção Particular retoma uma parte essencial da trajetória histórica do livro: o desenvolvimento do papel. Sabemos que os livros nem sempre tiveram a sua forma atual. A sua materialidade, por exemplo, sofreu grandes mudan- 
ças ao longo da história. Desde os mais antigos suportes de escrita (madeiras, ossos, peles de animais, papiro, entre outros) até os papéis que hoje utilizamos deu-se um longo percurso. É relevante o fato de que o primeiro título da Coleção Particular, uma coleção preocupada justamente com a materialidade do livro impresso, referencie o local de origem do material mais utilizado na produção de livros hoje, ou seja, o papel.

Primeiro amor utiliza um método de encadernação tradicional da China, mesmo país em que foi desenvolvido o papel. A chamada "encadernação chinesa" é aquela que junta folhas sem a necessidade de serem unidas em uma dobra interna, pois prende cada uma utilizando linha e agulha. Conforme aponta Lupton (2011), na costura chinesa as folhas são unidas de modo que a linha permaneça visivel na lombada e laterais do livro. Um recurso comum em tais encadernações é o de utilizar folhas dobradas no meio; a folha costumava ser dupla para absorver a tinta caligráfica utilizada na escrita oriental que penetrava nos papéis. Na edição de Primeiro amor, da Cosac Naify, não se trata de uma autêntica encadernação chinesa artesanal, pois a costura não é manual, mas sim feita em uma máquina Singer. Ainda assim, a presença das folhas duplas vazias em seu interior e com costura aparente remete fortemente a esse tipo de junção das páginas. A materialidade atual do livro é portanto homenageada pela editora ao escolher, no título inicial de sua coleção, encadernar a obra segundo uma técnica oriental, conforme o costume dos criadores do papel - os chineses.

Além da retomada sistemática dos aspectos históricos do livro, a Coleção Particular também evidencia aspectos de seu processo produtivo. Esse é o caso de Primeiro amor: já ao abrir a capa, o leitor se depara com a costura e a cola aparentes do miolo (fig. 8). A costura não liga as páginas por uma dobra interna, como é de praxe, mas é feita mecanicamente a uma curta distância da extremidade das folhas. Essas extremidades são unidas, além da costura, por uma camada de cola que as mantém fixas. Assim, tanto os pontos da costura quanto a área coberta de cola ficam visíveis no miolo, próximos à lombada. Colar e costurar são duas das etapas do processo produtivo comum de um livro: grandes folhas são primeiramente impressas, para logo em seguida serem dobradas em várias partes, formando cadernos, os quais são costurados pela dobra central, colados juntos e têm suas bordas excedentes refiladas (cortadas), resultando no miolo do livro. Portanto, pode-se afirmar que o projeto gráfico de Primeiro amor figurativiza duas etapas - costura e cola - do programa narrativo padrão de produção do miolo de um livro. 


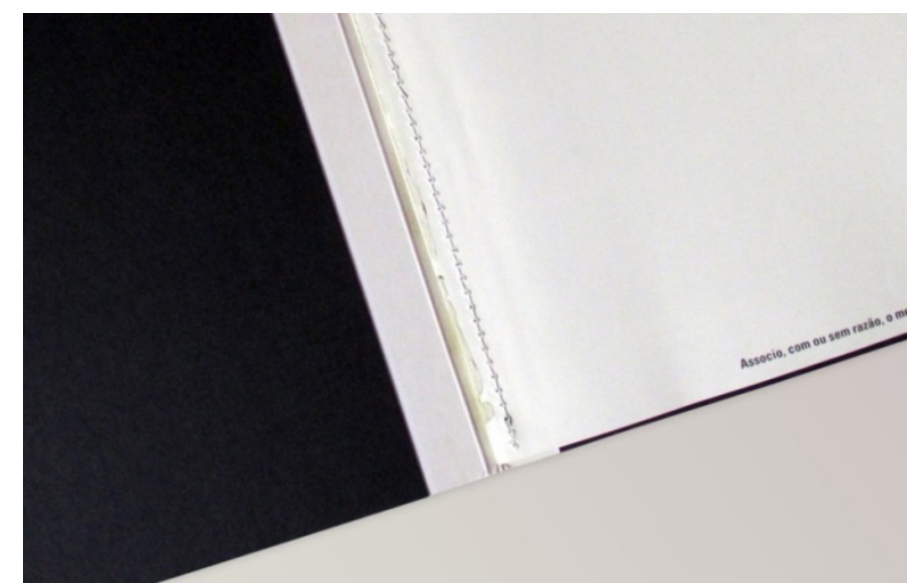

Figura 8: Detalhe da costura e da cola aparentes na abertura de Primeiro amor. Fonte: foto do autor.

Já a segunda publicação da coleção, Bartleby, o escrivão, nos arremessa a outro momento da história dos livros: as primeiras décadas do livro impresso. Há um detalhe curioso nessa publicação da Cosac Naify: todos os blocos de texto estão diagramados em uma tipografia de variação itálica. Estamos acostumados a ler livros impressos na versão romana das fontes, e encontrar um livro diagramado totalmente em itálico como Bartleby, o escrivão pode causar estranheza. O desenvolvimento da variação tipográfica chamada de "itálica" ocorreu no final do século XV, na prensa veneziana do editor Aldo Manuzio (FISCHER, 2006). Esse editor e impressor foi responsável por várias inovações na história do livro, como a criação dos livros de bolso, por exemplo. Manuzio, na tentativa de economizar espaço nas páginas, imprimiu obras inteiras em um estilo estreito baseado no cursivo da escrita comum; esses tipos cursivos ficaram, posteriormente, conhecidos como "itálicos" (FISCHER, 2006).

Mais que uma mera relação figurativa com a profissão do personagem-título (o escrivão), os tipos itálicos selecionados pela Cosac Naify constroem também uma relação de interdiscursividade com as publicações do final do Quatrocento de um dos mais célebres editores de todos os tempos.

Além disso, há outra referência histórica no projeto gráfico de Bartleby, o escrivão. O livro acompanha uma rígida lâmina plástica, com bordas agudas, que deve ser utilizada para romper as extremidades das folhas não-refiladas para acessar o texto verbal. Trata-se da retomada de uma prática comum em certos livros que, no passado, vinham sem o refile; os leitores, munidos de suas espátulas, realizavam eles mesmos o processo de separação das páginas.

Livros não-refilados não são usuais no mercado editorial brasileiro. Embora ainda presentes em determinadas obras voltadas para bibliófilos, de tiragem limitadíssima, a níveis comerciais não se encontram mais livros assim. Valendo-se desse recurso, que também se relaciona à própria trama da narrativa de Bartleby, a editora Cosac Naify proporciona aos leitores um mergulho na história do livro e no seu processo de produção.

Enquanto Primeiro amor nos demonstrava as etapas do seu processo produtivo (costurar, colar), Bartleby, o escrivão insere o leitor na dinâmica desse processo. Nessa publicação, o leitor é um sujeito que participa ativamente do programa narrativo 
de construção do objeto livro. A editora Cosac Naify não nos entrega um produto completamente acabado: para que se tenha acesso à obra, não basta comprá-la, é necessário participar do seu processo de feitura. No primeiro passo desse programa de produção, o sujeito deve descosturar a capa, tomando a dianteira a partir das provocações deixadas pela editora (a vibrante linha vermelha que entra em conflito com o verde da capa, a sutil ponta da linha solta a partir do último nó). Na etapa seguinte, cortam-se as páginas com a espátula que acompanha o livro (fig. 9).

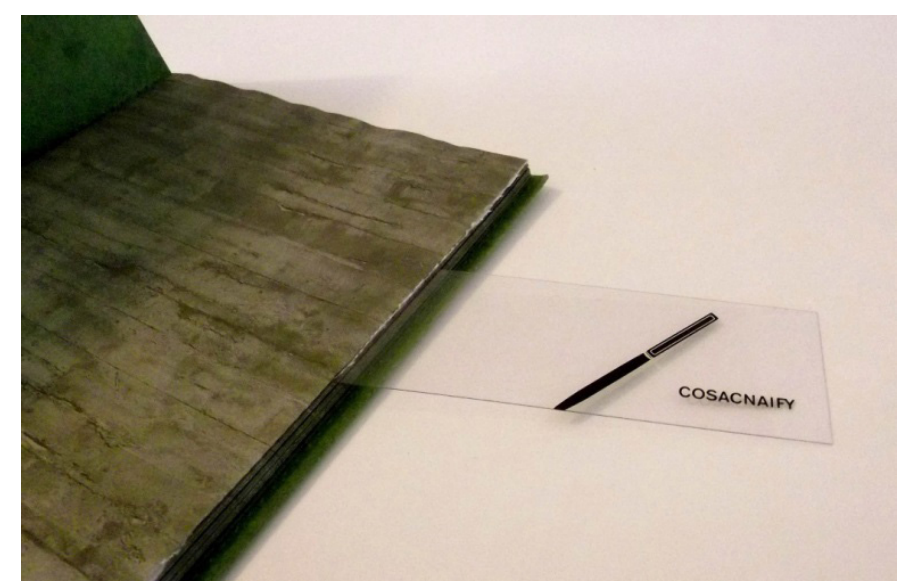

Figura 9: 0 ato de cortar as páginas de Bartleby, o escrivão é realizado com o auxílio da espátula que acompanha o livro. 0 destinador Cosac Naify acompanha o leitor durante todo o processo de abertura das folhas. Fonte: foto do autor.

Os materiais utilizados em Bartleby, o escrivão são as matérias-primas da fabricação do livro: papel, linha, tinta, cola e o plástico da espátula. Porém, esses materiais não vêm de início transformados em um objeto pronto, em um livro. Trata-se de uma espécie de "pré-livro", pois ainda não é dotado de todas as funções que o livro comum apresenta: possibilitar a passagem das páginas, o ato de folhear e mesmo de permitir a leitura do conteúdo verbal. No entanto, os materiais já sofreram coerções e passaram por um certo processo de fabricação, pois o papel está impresso, cortado em um certo formato, ordenado e colado. O que opera a transformação final do "pré-livro" em objeto é justamente o fazer ativo do leitor, que desconstrói a costura e rompe as páginas.

Mais que um processo de produção do objeto, vemos que Bartleby, o escrivão coloca o leitor em um programa narrativo que é histórico, pois remete a um certo momento da evolução do livro impresso em que este era entregue sem o refile, e que é sensível. Trata-se de um percurso de formação do leitor que visa educá-lo em relação à diacronia do livro e às suas qualidades sensíveis.

Vimos portanto que a Coleção Particular retoma vários aspectos da história do livro: a invenção do papel e a costura chinesa em Primeiro amor; os tipos itálicos e o livro não-refilado em Bartleby, o escrivão. Nas demais obras da coleção, outros momentos da história do livro são retomados: a direcionalidade vertical dos rolos de papiro gregos, os livros ilustrados característicos do final do século XVI, a distribuição do livro pelos mascates e pelos correios, a sociedade de consumo na época dos bestsellers, a problemática do livro como mercadoria na época dos supersellers etc.

Também são explicitadas nas obras da Coleção Particular certas características 
do processo produtivo do livro: a cola e a costura aparente em Primeiro amor; a inserção do leitor no programa de produção do livro em Bartleby, o escrivão. Nos outros títulos da coleção, outros aspectos do processo produtivo ficam evidenciados: o sistema de dobra dos formatos comerciais do papel, a reprodução ampliada das retículas de impressão, a ordenação dos cadernos do miolo visíveis em uma lombada descoberta, o uso das diferentes tintas de impressão, apenas para listar alguns.

Assim vemos como a editora Cosac Naify se vale das diversas etapas da produção do livro e faz com que ações como imprimir, dobrar, costurar, ordenar, colar e cortar não sejam apenas passos para construí-lo, mas sim passos para construir o próprio sentido do livro. Os discursos dos livros da Coleção Particular incorporam aspectos de um outro discurso - os modos de produzir um livro e o seu desenvolvimento histórico -, que serve de contexto para a compreensão do sentido das publicações. Essa história, estrutura e modo de produção convencionais são ora homenageados, ora subvertidos pelas publicações da coleção.

\section{VANGUARDA: TRADIÇÃO E INOVAÇÃO}

Por meio de uma forte estratégia de design a totalidade da Coleção Particular produz com cada um de seus livros uma experiência sensível de leitura. A plasticidade de tais livros responde tanto ao que é proposto pela dimensão verbal de cada obra, quanto insere-se em uma lógica do sentido global da coleção e da editora a partir de traços identitários que são reiterados em cada uma das publicações. O resultado são livros que se sobressaem no meio editorial, interpelam o leitor e fazem com que ele apreenda o sentido da obra - tátil e visualmente, na relação entre o seu corpo e o corpo do livro.

Essas publicações estão inseridas em um contexto em que os livros impressos precisam cada vez mais reafirmar-se em sua materialidade para se fazerem desejados. Conforme a visão do editor americano Richard Nash (2013), vários relatos atuais do mercado editorial veem a indústria do livro impresso correndo um forte risco mas, no entanto, o capitalismo e as forças mercadológicas também podem ser úteis para animar o mercado de livros. Há um espaço para a comercialização dos exemplares impressos que pode ser potencializado pela diversificação da oferta: um mesmo livreiro pode vender desde brochuras baratas até edições elegantes em capa dura, edições especiais dentro de caixas, edições limitadas com assinatura do próprio autor, e assim por diante. (NASH, 2013).

Essas ofertas cada vez mais diversificadas de livros impressos encontram respaldo em leitores também mais especializados e conscientes da linguagem do livro. Se o consumidor contemporâneo é um sujeito "mais sofisticado" e necessita de uma quantidade gradativamente maior de informações e comparações para que faça suas escolhas, como propõem Lipovetsky e Serroy (2011), é porque também os produtos contemporâneos complexificaram-se. Muitos produtos culturais atuais inovam em recursos de linguagem e na maneira como constroem sua própria significação, 
exigindo uma leitura atenta e um público disposto a enfrentar processos semióticos complexos.

É assim que os livros da Coleção Particular mostram-se ao mundo em sua complexidade de sentidos e, para que sejam compreendidos em sua totalidade, o leitor deve ser educado, orientado passo a passo no percurso de elaboração e nos processos de linguagem do livro impresso. As relações entre o projeto gráfico e a dimensão verbal das obras estão postas no objeto e o leitor é desafiado a empreender uma leitura atenta e lançar um olhar apurado para decifrá-las. As qualidades sensíveis são exploradas por esses livros em procedimentos estésicos que exigem do leitor (ou do analista) uma postura de abertura ao seu próprio sentir para que possa compreender os sentidos manifestados nas publicações.

De tal modo, a editora Cosac Naify define-se, no mercado editorial brasileiro, pela sua relação de formação da sensibilidade e da estética apreciativa dos seus leitores, ao mesmo tempo em que abre espaço mercadológico no Brasil para um determinado tipo de publicação - obras com um design mais sensível.

Além de uma exploração da plasticidade do livro, depreende-se da análise das obras diversas relações metadiscursivas que elas mantêm com a história, estrutura e processos produtivos do livro (além das relações com diversas mídias e artes, que não estão detalhadas nesse artigo), sendo que essas relações são também fundamentais na construção dos sentidos da Coleção Particular.

O efeito de sentido de "vanguarda" atribuído à editora Cosac Naify é figurativizado nas diversas escolhas de design das publicações da Coleção Particular. Se a vanguarda nas artes pode ser entendida como a ruptura em relação às artes tradicionais, o termo "vanguarda" é utilizado de uma maneira mais geral referindo-se a um certo modo de estar à frente de seu tempo, de ser inventivo e de antecipar tendências, bem como de liderar uma maneira de agir e/ou pensar em algum campo específico.

Após analisar cada um dos livros da Coleção Particular, e mais especificamente ao fim do levantamento das relações interdiscursivas com os discursos do livro, podemos chegar a uma semiotização do termo "vanguarda" no contexto específico da Cosac Naify, que diz respeito à maneira como ela explora a forma do livro. A valorização da materialidade do livro, a exploração de sua plasticidade e de seu projeto gráfico é o que vem se desenhando como possibilidade de permanência e de valorização do livro impresso frente à popularidade das publicações digitais. Esse modo de pensar e fazer o livro é o que vem sendo adotado pela editora Cosac Naify, especialmente em sua Coleção Particular, que é um dos carros-chefe nessa empreitada. Esse tipo de vanguarda - de liderança em seu campo - não se faz rompendo totalmente com o passado, portanto, mas sim retomando da história do livro tudo aquilo que propicia uma sensibilização do sujeito leitor. A vanguarda da Cosac Naify apresenta-se, então, como um termo complexo que une a /tradição/ e a /inovação/ (esquema 1). 


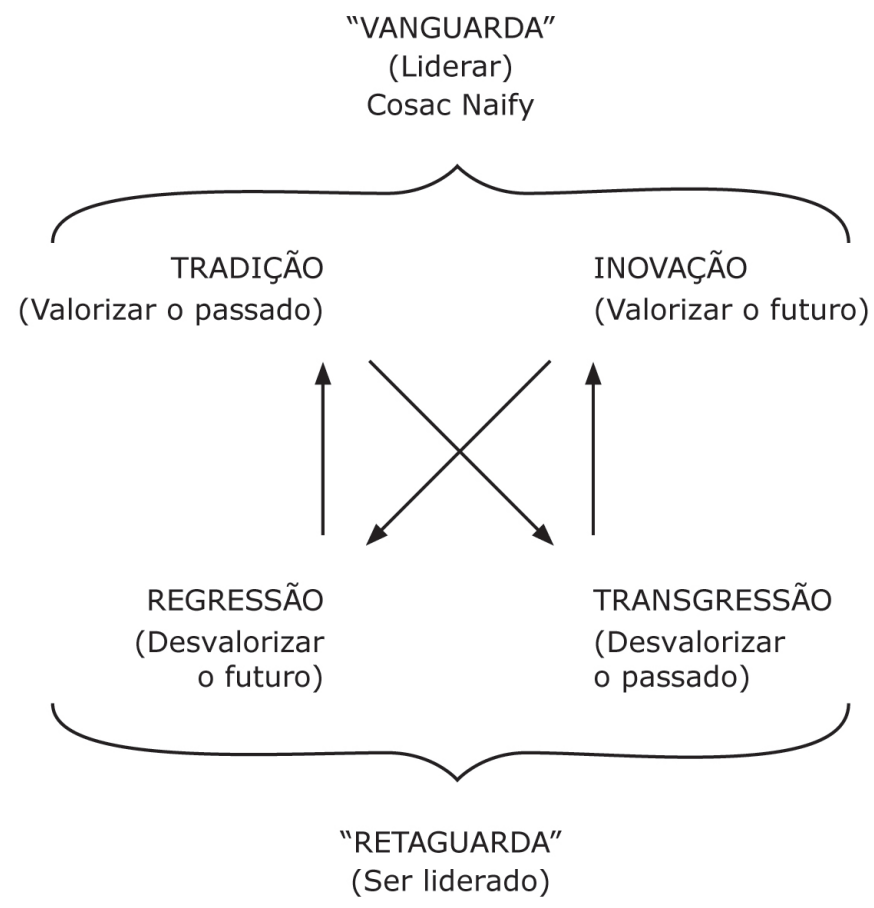

Esquema 1: Quadrado semiótico da /tradição/ e da /inovação/, exibindo a construção de um certo tipo de "vanguarda" que é característico da Cosac Naify.

A valorização do passado, ou seja, a euforização da postura da /tradição/ é percebida quando a editora insere sensivelmente o seu leitor em um percurso histórico ao fazê-lo rasgar as páginas do livro não-refilado (Bartleby), ler as pinceladas do nanquim na encadernação chinesa (Primeiro amor), tatear a reprodução de um jornal do século XIX etc., retomando características da história do próprio livro, das artes e das mídias. Mas ao mesmo tempo em que realiza essa retomada, a editora inova em diversos aspectos do livro, propondo dobras, invólucros, materialidades significantes incomuns e muitas vezes ainda não assimiladas pelo mercado editorial brasileiro, euforizando uma postura de /inovação/.

Essa atitude complexa que integra a /tradição/ e a /inovação/ em um mesmo processo de construção de sentido pode ser vista e sentida se pensamos na estrutura "canônica" de um livro. Enquanto certos elementos tradicionais do livro são mantidos em algumas das publicações, há em outras uma quebra sistemática das convenções estruturais, sempre com vistas a enriquecer a experiência sensível do livro. $O$ interessante em abordar a inovação do ponto de vista da produção de sentido (da Semiótica, portanto) é perceber como os processos inovadores de design realizados por essa coleção culminam, nos objetos finais, em um efeito de sentido de "vanguarda" que está posto nos livros e que é sentido sensivelmente pelos sujeitos que se poem a interagir com eles.

A editora assume assim um papel de liderança em um certo modo de pensar e produzir livros, retomando valores tradicionais de sua história e apostando em aspectos inovadores. Aos concorrentes que negarem qualquer tipo de inovação em seus processos produtivos apenas por comodidade (uma forma de regressão) ou romperem com as tradições apenas pelo prazer de rompê-las (com o único propósito de 
transgredir), cabe nesse cenário somente um papel: o de ser liderado.

\section{Referências}

COSAC NAIFY. A fera na selva inova em projeto visual e comemora os dez anos da editora Cosac Naify. Disponível em: <http://editora.cosacnaify.com.br/legacy/ fera/>. Acesso em: 29 maio 2013.

FIORIN, José Luiz. Elementos de análise do discurso. 15. ed. São Paulo: Contexto, 2011.

FISCHER, Steven Roger. História da leitura. Tradução Claudia Freire. São Paulo: Editora UNESP, 2006.

GREIMAS, A. J.; COURTÉS, Joseph. Dicionário de Semiótica. 2. ed. São Paulo: Contexto, 2011.

LIPOVETSKY, Gilles; SERROY, Jean. A cultura-mundo. Tradução Maria Lúcia Machado. 1aㅡ reimpressão. São Paulo: Companhia das Letras, 2011.

LUPTON, Ellen (Ed.). A produção de um livro independente - Indie Publishing: um guia para autores, artistas e designers. Tradução Maria Lúcia L. Rosa. São Paulo: Edições Rosari, 2011.

MACHADO, Samir. Sobrecapas: Avenida Niévski. 09 de agosto de 2012. Disponível em: <http://sobrecapas.blogspot.com.br/2012/08/avenida-nievski.html>. Acesso em: 29 maio 2013.

NASH, Richard. Qual o negócio da literatura? Tradução Adriano Scandolara. Serrote, São Paulo, n. 14, p. 163-185, 2013. 